\title{
PEMBINAAN DAN PENDAMPINGAN PERILAKU HIDUP BERSIH DAN SEHAT (PHBS) DI MADRASAH IBTIDAIYAH HIDAYATUL INSAN KOTA PALANGKA RAYA
}

\section{(The Development and Accompaniment of Clean and Healthy Behavior in Madrasah Ibtidaiyah Hidayatul Insan Palangka Raya City)}

\author{
Nurhalina, Suratno dan Jarot Marchel
}

Program Studi Analis Kesehatan Fakultas Ilmu Kesehatan Universitas Muhammadiyah Palangkaraya

JI. RTA Milono Km.1,5 Palangka Raya, Kalimantan Tengah 73111

e-mail : nurhalina@umpalangkaraya.ac.id

\begin{abstract}
Household Health Survey on 2013 shows that 60\% children's disease in Palangka Raya continue to increase especially related to clean and healthy behavior. Islamic Primary School (MI) Hidayatul Insan Palangka Raya is one of primary education institution in Palangka Raya at risk of disease transmission. It is because the school has not implement clean and healthy behavior in the school environtment optimally.

Clean and healthy behavior development and accompaniment in MI Hidayatul Insan Palangka Raya aimed to provide assistance to the school in planning clean and healthy behavior policy, supporting infrastructure preparation, education, observation and evaluation of clean and healthy behavior implementation.

The method of the communty service involved preparation, implementation and evaluation. The output of the community service were the school has implemented clean and healthy behavior; clean and healthy school environtment; increasing student achievement; and increasing public interest to send their children to the school.
\end{abstract}

Keywords: development, accompaniment, clean and healthy behavior, school healthy

\section{Abstrak}

Hasil Survei Kesehatan Rumah Tangga Tahun 2013 menunjukkan bahwa 60\% penyakit pada anak sekolah di Kota Palangka Raya terus meningkat terutama yang berhubungan dengan perilaku hidup bersih dan sehat (PHBS). Madrasah Ibtidaiyah (MI) Hidayatul Insan Palangka Raya merupakan salah satu lembaga pendidikan dasar di Kota Palangka Raya yang berisiko penularan penyakit karena belum maksimalnya penerapan PHBS di lingkungan sekolah.

Tujuan kegiatan pembinaan dan pendampingan PHBS di MI Hidayatul Insan Palangka Raya adalah untuk memberikan pendampingan kepada sekolah dalam melakukan perencanaan kebijakan PHBS, penyiapan infrastruktur pendukung, sosialisasi serta monitoring dan evaluasi penerapan PHBS di sekolah MI Hidayatul Insan Palangka Raya.

Metode pelaksanaan pengabdian kepada masyarakat ini meliputi persiapan kegiatan, pelaksanaan dan evaluasi kegiatan. Luaran penelitian diperoleh informasi bahwa warga sekolah telah menerapkan PHBS dalam kehidupan sehari-hari, lingkungan sekolah yang bersih dan sehat; meningkatnya prestasi akademik siswa; dan meningkatnya animo masyarakat untuk menyekolahkan anaknya di MI Hidayatul Insan Kota Palangka Raya.

Kata kunci: pembinaan, pendampingan, perilaku hidup bersih dan sehat, kesehatan sekolah 


\section{PENDAHULUAN}

\section{Analisis Situasi}

Hasil dari Riset Kesehatan Dasar pada Tahun 2013 menunjukkan bahwa rumah tangga yang mempraktekkan Perilaku Hidup Bersih dan Sehat (PHBS) baru mencapai 38,7\%, dimana dari 10 indikator PHBS pencapaian di perkotaan sebesar $42,3 \%$ dan pedesaan mencapai $22,9 \%$. Hal ini menunjukkan bahwa capaian program masih jauh dari target nasional. Rendahnya capaian indikator PHBS dalam rumah tangga maupun di sekolah memberikan konstribusi terhadap peningkatan gangguan kesehatan terhadap anak-anak, karena kesehatan anakanak sangat dipengaruhi oleh lingkungan dan perilaku orang-orang yang ada di sekitar mereka.

Hasil dari Survei Kesehatan Rumah Tangga (SKRT) pada tahun 2013 menunjukkan angka kecacingan pada anak mencapai 40-60\%, anemia $23,2 \%$, karies dan periodontal $74,4 \%$ dan TB pada anak 23\%. Data hasil Survei Sosial Ekonomi (Susenas) pada tahun 2013 menyebutkan bahwa sekitar $3 \%$ anak-anak mulai merokok sejak kurang dari 10 tahun. Presentase perokok tertinggi (64\%) adalah kelompok remaja (15-19 tahun), artinya anak-anak merupakan kelompok yang rentan terhadap bahaya rokok. Oleh karena itu, penanaman nilai-nilai kehidupan yang berparadigma sehat perlu ditanamkan sejak dini pada anak-anak dan orang-orang di sekitar mereka dalam hal ini rumah tangga dan sekolah.

Penerapan PHBS di sekolah merupakan kebutuhan seiring munculnya berbagai penyakit yang umumnya berkaitan dengan PHBS. Upaya PHBS di sekolah merupakan sekumpulan perilaku yang dipraktikkan oleh peserta didik, guru, dan masyarakat di lingkungan sekolah atas dasar kesadaran sebagai hasil pembelajaran, sehingga secara mandiri mampu mencegah penyakit, meningkatkan kesehatannya, serta berperan aktif dalam mewujudkan lingkungan sehat. Penerapan PHBS ini dapat dilakukan melalui pendekatan Usaha Kesehatan Sekolah (UKS).

Madrasah Ibtidaiyah (MI) Hidayatul Insan Kota Palangka Raya merupakan salah satu lembaga pendidikan dasar yang terletak di Kelurahan Langkai Kecamatan Pahandut Kota Palangka Raya. Letak sekolah yang tak jauh dari sungai menjadikan siswa rentan terhadap penularan berbagai macam penyakit menular, sebab masyarakat sekitar kerapkali membuang sampah di sungai. Ditambah lagi kebiasaan siswa yang mengonsumsi jajanan yang tidak higenis dan kondisi sanitasi yang tidak memenuhi syarat kesehatan. Hasil observasi menunjukkan bahwa sekolah tersebut telah memiliki UKS namun kegiatan yang dilakukan belum maksimal. Hal tersebut disebabkan karena minimnya keterampilan sumber daya manusia dalam promosi kesehatan, minimnya sarana dan prasarana serta belum tersedianya anggaran guna mendukung penerapan PHBS di sekolah.

\section{Permasalahan}

Berdasarkan informasi diketahui bahwa perencanaan akan program PHBS di MI Hidayatul Insan Palangka Raya sudah ada, namun belum dilaksanakan secara terpadu baik lintas program maupun lintas bidang. Padahal tujuan dan sasaran kegiatan ini adalah untuk menerapkan pembudayaan hidup bersih dan sehat di sekolah secara berkesinambungan, sehingga perlu melibatkan seluruh warga sekolah baik pimpinan, guru, siswa, komite sekolah, orang tua, penjaga 
kantin dan satpam serta pihak eksternal lainnya mulai dari perencanaan, pengorganisasian, pencatatan dan pelaporan serta monitoring dan evaluasi. Oleh karena itu, dalam rangka menciptakan perubahan perilaku di sekolah maka perlu dilakukan pembinaan dan pendampingan PHBS sehingga program PHBS dapat didukung oleh semua pihak.

\section{Tujuan}

Perguruan tinggi sebagai pencetak generasi muda berkualitas mempunyai peran dalam melaksanakan Tri Dharma Perguruan Tinggi (Pendidikan, Penelitian dan Pengabdian Kepada Masyarakat). Untuk bidang pengabdian kepada masyarakat dituntut senantiasa responsif terhadap masalah yang terjadi pada masyarakat sekitar sebagai bentuk tanggung jawab sosial terhadap keilmuan yang dimiliki. Berdasarkan uraian di atas, dosen-dosen di Program Studi Analis Kesehatan UM Palangkaraya melaksanakan kegiatan pembinaan dan pendampingan PHBS di MI Hidayatul Insan Kota Palangka Raya. Kegiatan pengabdian kepada masyarakat ini diharapkan dapat memberikan pembinaan dan pendampingan kepada pihak sekolah dalam melakukan pengorganisasian penerapan PHBS, sosialisasi PHBS, penyiapan sarana dan prasarana serta monitoring dan evaluasi penerapan PHBS di sekolah.

\section{METODE PELAKSANAAN}

\section{Waktu dan Tempat}

Kegiatan pengabdian kepada masyarakat ini dilaksanakan selama 3 bulan menggunakan pendanaan pada Tahun Anggaran 2015. Kegiatan pengabdian kepada masyarakat ini dilakukan di
MI Hidayatul Insan Kota Palangka Raya, tepatnya beralamat di Jalan Sulawesi No. 67 Kelurahan Langkai Kecamatan Pahandut Kota Palangka Raya Kalimantan Tengah.

\section{Sasaran Kegiatan}

Sasaran dalam kegiatan ini meliputi sasaran primer, sekunder dan tersier. Sasaran primer yaitu sasaran utama dalam hal ini siswa dan guru di MI Hidayatul Insan Kota Palangka Raya. Sasaran sekunder yaitu kelompok/individu yang dapat mempengaruhi perubahan perilaku individu lainnya, dalam hal ini kepala sekolah, guru, orang tua murid, kader kesehatan sekolah, tokoh masyarakat, petugas kesehatan dan lintas sektor terkait, PKK. Sasaran tersier yaitu sasaran yang diharapkan dapat menjadi unsur pembantu dalam menunjang atau mendukung pendanaan, sarana dan prasarana guna mendukung pelaksanaan PHBS di MI Hidayatul Insan Palangka Raya, dalam hal ini Kantor Kelurahan Langkai, Kantor Kecamatan Pahandut, Puskesmas Pahandut, Dinas Kesehatan Kota Palangka Raya dan Dinas Pendidikan Kota Palangka Raya.

\section{Metode Kegiatan}

Metode kegiatan pengabdian kepada masyarakat ini adalah melakukan pendampingan dan pembinaan PHBS, dengan beberapa tahapan yaitu: 1). pendampingan sekolah dalam melakukan analisis situasi; 2). pendampingan pembentukan kelompok kerja; 3). pendampingan pembuatan kebijakan PHBS di sekolah; 4). Model Pendampingan Penyiapan Infrastruktur; 5). pendampingan sosialisasi penerapan PHBS di sekolah; 6). pendampingan penerapan PHBS di sekolah; 7). pendampingan pemantauan dan evaluasi; dan 8) pendampingan tindak lanjut. 


\section{Solusi yang Ditawarkan}

Solusi yang ditawarkan untuk menyelesaikan prioritas masalah di MI Hidayatul Insan Palangka Raya adalah: a). dilaksanakan pengabdian kepada masyarakat berupa pendampingan dan pembinaan PHBS, b). adanya penerapan warga sekolah tentang PHBS dalam kehidupan sehari-hari, c). adanya lingkungan sekolah yang bersih dan sehat, d). meningkatnya prestasi akademik siswa akibat penerapan PHBS, dan e). meningkatnya animo masyarakat untuk menyekolahkan anaknya di MI Hidayatul Insan Kota Palangka Raya akibat pengaruh secara langsung dan tak langsung dari penerapan PHBS di sekolah.

\section{HASIL DAN PEMBAHASAN}

Kegiatan pengabdian kepada masyarakat yang bertema pendampingan perilaku hidup bersih dan sehat (PHBS) di MI Hidayatul Insan Kota Palangka Raya dilaksanakan melalui beberapa tahap yaitu persiapan kegiatan, pelaksanaan dan evaluasi.

\section{Persiapan Kegiatan Pengabdian Kepada Masyarakat}

Tim pengabdian kepada masyarakat melakukan observasi ke Ml Hidayatul Insan Palangka Raya yang terletak di Jalan Sulawesi Kota Palangka Raya. Berdasarkan hasil observasi diperoleh informasi tentang minimnya penerapan PHBS yang ditandai dengan kurangnya kebersihan sekolah baik halaman, kantin, toilet dan ruang kelas. Hal tersebut dimungkinkan karena belum adanya kebijakan sekolah tentang penerapann PHBS, serta SDM, sarana dan prasarana pendukung. Selain itu kebiasaan masyarakat sekitar membuang sampah sembarangan dan di sungai cukup mengganggu estetika sekolah.

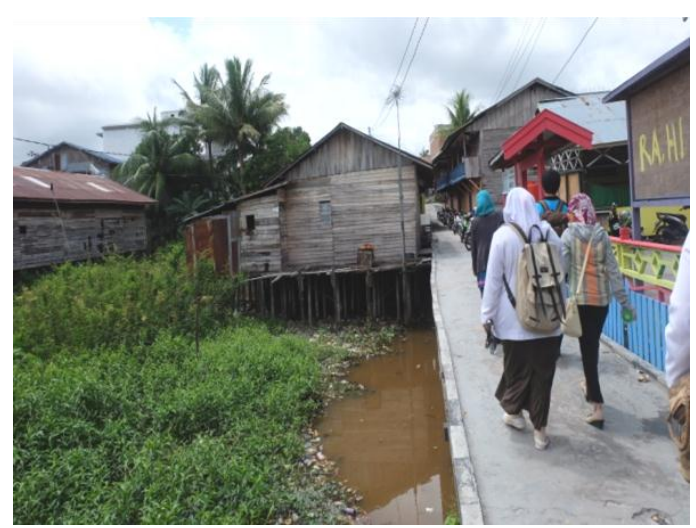

Gambar 1. Kondisi lingkungan di sekitar sekolah MI Hidayatul Insan Palangka Raya

\section{Pelaksanaan Kegiatan}

\section{Tahap pendampingan sekolah dalam melakukan analisis situasi}

Tahap pendampingan kepada sekolah dalam melakukan analisis situasi ditujukan sebagai upaya mendampingi sekolah dalam hal ini penentu kebijakan/pimpinan sekolah melakukan pengkajian ulang tentang ada tidaknya kebijakan tentang PHBS di sekolah serta bagaimana sikap dan perilaku khalayak sasaran (siswa, warga sekolah dan masyarakat lingkungan sekolah) terhadap kebijakan PHBS di MI Hidayatul Insan Palangka Raya. Kegiatan ini dilakukan melalui diskusi dengan kepala sekolah, guru dan petugas UKS MI Hidayatul Insan sehingga diperoleh gambaran tentang masalahmasalah yang dihadapi dalam penerapan PHBS di MI Hidayatul Insan Palangka Raya. 


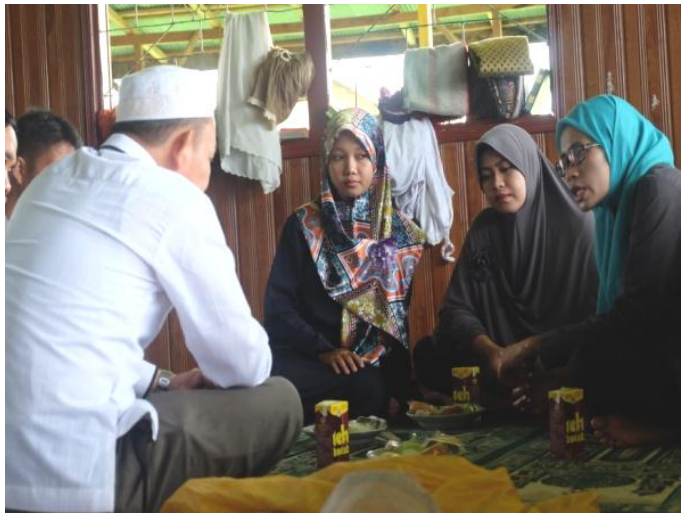

Gambar 2. Kegiatan diskusi dengan kepala sekolah, guru dan petugas UKS MI Hidayatul Insan Palangka Raya

Salah satu persoalan yang dihadapi adalah minimnya keterampilan sumber daya manusia dalam melaksanakan promosi kesehatan tentang PHBS dan belum adanya tenaga khusus yang menangani kegiatan UKS. Selama ini petugas UKS yang ada masih merangkap sebagai guru dan belum sepenuhnya mengerti tentang 10 indikator PHBS atau penerapan PPHBS kepada warga sekolah. Mengingat keterbatasan dari petugas UKS karena harus mengerjakan tugas rangkap maka untuk itu perlu dipikirkan upaya untuk meningkatkan keterampilan petugas UKS di bidang promosi PHBS di sekolah agar petugas memahami pelaksanaan program PHBS dengan baik maka perlu diberikan pelatihan atau pendidikan kepada petugas UKS agar dapat meningatkan pengetahuan dan keterampilannya sehingga memiliki keahlian dalam promosi kesehatan kepada warga sekolah. Selain itu, diharapkan guru-guru lainnya agar dapat mendukung program PHBS. Senada dengan Diana dkk. (2013) yang menyatakan bahwa rendahnya tingkat pengetahuan anak/siswa terhadap PHBS disebabkan karena kurangnya peran guru dan tenaga kesehatan dalam memberikan informasi mengenai PHBS, kurangnya pelatihan terhadap guru sehingga guru tidak bisa mengajarkan PHBS pada siswanya.

Dana promosi kesehatan di sekolah belum ada, sehingga kegiatan yang dilakukan masih belum maksimal. Begitu pula dengan sarana dan prasarana penunjang, sarana media cetak yang dibuat sekolah ataupun distribusi dari dinas kesehatan setempat sangat terbatas. Perencanaan program PHBS di sekolah sudah dilaksanakan, namun perencanaan tersebut belum dilaksanakan secara terpadu baik lintas program maupun lintas bidang.

Hasil diskusi dengan para guru bahwa pengorganisasian untuk pelaksanaan program PHBS di sekolah secara terpadu belum ada. Selama ini hanya dilakukan oleh petugas UKS padahal untuk penerapan perilaku hidup bersih dan sehat adalah perlunya komitmen dari semua instansi terkait untuk membina dan membentuk pengorganisasian baik di lingkungan kelas, kantin maupun di lingkungan sekitar sekolah sehingga memudahkan untuk melakukan kegiatan dan evaluasi secara kontinyu dan dapat memberikan alternatif pemecahan masalah yang dihadapi sekolah.

Kondisi lain menunjukkan bahwa sistem pencatatan dan pelaporan PHBS di sekolah belum ada. Hal ini disebabkan karena belum adanya pokja khusus yang ditunjuk untuk melakukan pencatatan dan pelaporan. Kegiatan ini masih diserahkan kepada petugas UKS dan mereka belum membuat laporan penerapan PHBS di sekolah karena belum ada tuntutan dari pimpinan sekolah dan tidak tahu ditujukan kemana. Di samping itu, sekolah hanya melakukan evaluasi pada saat rapat atau 
pertemuan dengan guru-guru yang bukan pembahasan khusus mengenai penerapan PHBS di sekolah. Mengingat perubahan perilaku butuh waktu yang lama maka perlu adanya pemantauan dan evaluasi yang rutin, sehingga setiap ditemui masalah atau kendala dalam penerapan PHBS segera dibahas dalam pertemuan rutin. Selain itu, evaluasi perlu melibatkan dari pihak komite sekolah, orang tua dan masyarakat di lingkungan sekolah agar kegiatan dapat berkesinambungan dan menjadi budaya di tengah-tengah masyarakat.

\section{Tahap pendampingan pembentukan kelompok kerja}

Tahap ini bertujuan agar sekolah mempunyai bagian khusus dalam unit UKS yang bertugas melakukan promosi kesehatan di sekolah. Pada tahap ini tim dan pihak pimpinan MI Hidayatul Insan Palangka Raya berdialog dengan guru, komite sekolah dan tim pelaksana atau tim Pembina UKS tentang maksud dan tujuan manfaat penerapan PHBS di sekolah, meminta masukan akan penerapan PHBS di sekolah, antisipasi kendala serta alternatif solusi, menetapkan penanggung jawab PHBS di sekolah dan mekanisme pengawasannya. Pada tahap ini, pihak sekolah secara bersama-sama membentuk kelompok kerja penerapan PHBS di MI Hidayatul Insan Palangka Raya yang terdiri dari 6 orang guru.

\section{Tahap pendampingan pembuatan kebijakan PHBS di sekolah}

Tahap ini ditujukan agar kelompok kerja membuat kebijakan jelas, tujuan dan cara melaksanakan PHBS di sekolah. Kegiatan pendampingan pembuatan kebijakan PHBS di MI
Hidayatul Insan dihadiri oleh kepala sekolah, guru dan pengelola UKS melalui kegiatan rapat rutin sekolah yang diadakan setiap hari Jum'at. Dalam pertemuan tersebut dibahas petunjuk teknis pelaksanaan PHBS di sekolah dan aturan-aturan terkait. Pada minggu kedua pendampingan ditetapkan petunjuk teknis penerapan PHBS di MI Hidayatul Insan Palangka Raya.

\section{Tahap pendampingan penyiapan infrastruktur}

Tahap pendampingan dan penyiapan infrastruktur ini, tim mendampingi sekolah dalam membuat surat keputusan tentang penanggung jawab dan pengawas PHBS di sekolah serta membantu sekolah dalam menyiapkan sarana dan prasarana pendukung. Instrumen pengawasan materi sosialisasi penerapan PHBS di sekolah, serta pembuatan dan penempatan pesan di tempat-tempat strategis di sekolah MI Hidayatul Insan Palangka Raya.

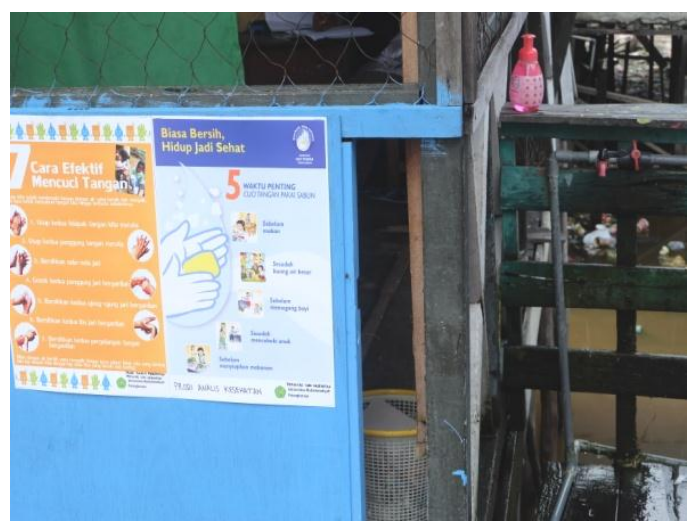

Gambar 3. Penyediaan sabun cuci tangan dan penempatan poster cara mencuci tangan yang benar di dekat tempat mencuci tangan (tempat strategis) dilakukan oleh tim pengabdian kepada masyarakat 


\section{Tahap sosialisasi penerapan PHBS di sekolah}

Tahap ini dilaksanakan oleh tim pengabdian kepada masyarakat dengan membantu petugas penanggung jawab PHBS di sekolah MI Hidayatul Insan Palangka Raya dalam melakukan sosialisasi penerapan PHBS di sekolah, meliputi sosialisasi penggunaan jamban sehat dan air bersih, larangan merokok di sekolah dan kawasan tanpa rokok di sekolah, membuang sampah pada tempatnya dan lain-lain.

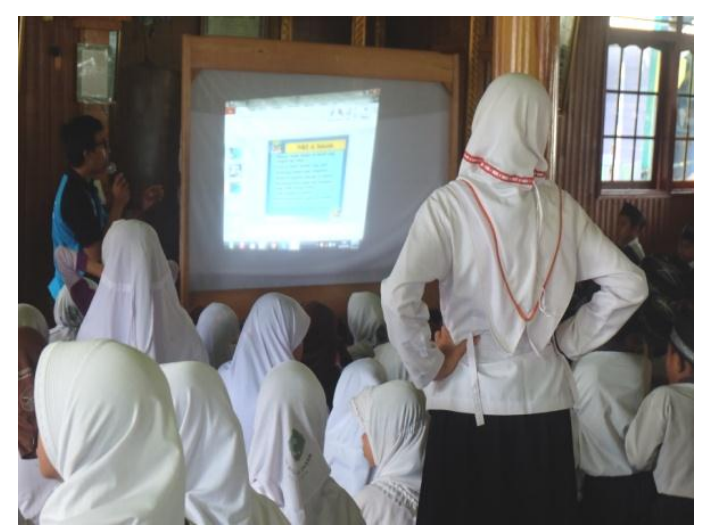

Gambar 4. Sosialisasi penerapan PHBS kepada siswa-siswi MI Hidayatul Insan Palangka Raya

Sosialisasi ini dilakukan guna meningkatkan pengetahuan dan pemahaman siswa-siswi mengenai PHBS di sekolah. Hal ini dapat meningkatkan implementasi perilaku PHBS di sekolah. Seperti yang dilaporkan oleh Sulastri dkk. (2014) bahwa ada hubungan antara tingkat pengetahuan dengan perilaku anak sekolah tentang perilaku hidup bersih dan sehat di sekolah dasar.

\section{Tahap pendampingan penerapan PHBS di sekolah}

Tahap penerapan PHBS di sekolah ini dilakukan dengan upaya (1) Mendorong sekolah agar menanamkan nilai-nilai PHBS kepada siswa sesuai dengan kurikulum yang berlaku (kurikuler); (2) Mendorong sekolah agar melakukan kerja bakti dan lomba kebersihan kelas secara rutin; (3) Aktivitas kader kesehatan kecil/dokter kecil; (4) Tim membantu melakukan pemeriksaan kualitas air secara sederhana; (5) Mendorong sekolah agar melakukan pemeliharaan jamban sekolah; (5) Tim memberikan demo gerakan cuci tangan/gosok gigi yang benar melalui lagu dan musik; (6) Mendorong sekolah agar membudayakan olah raga yang teratur dan terukur; (7) Pemeriksaan rutin kebersihan, meliputi kuku, rambut, telinga, gigi dan sebagainya; (8) Mendorong sekolah agar melakukan bimbingan hidup bersih dan sehat melalui konseling secara rutin; (9) Melakukan kegiatan penyuluhan atau latihan keterampilan dengan melibatkan peran aktif guru dan orang tua, antara lain melalui penyuluhan kelompok, pemutaran video/film, penampatan poster, penyebaran leaflet dan membuat majalah dinding; (10) Mendorong sekolah melakukan pengawasan dan penerapan sanksi pengawas, mencatat pelanggaran dan menerapkan sanksi sesuai dengan peraturan yang ada.

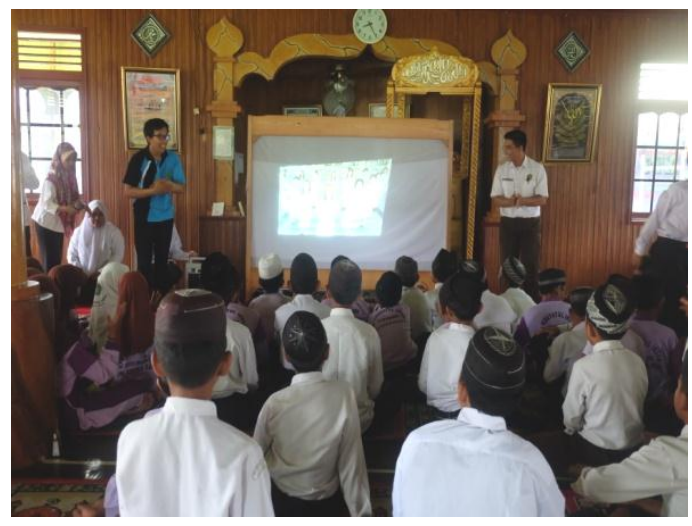

Gambar 5. Tim memberikan demo gerakan cuci tangan/gosok gigi yang benar dengan diiringi musik dan lagu 


\section{Tahap pendampingan pemantauan dan evaluasi}

Tahap ini tim pengabdian kepada masyarakat membantu sekolah dalam melakukan pemantauan dan evaluasi PHBS di sekolah melalui upaya: (1) Mendorong sekolah melakukan pemantauan dan evaluasi secara periodik tentang kebijakan yang telah dilaksanakan; Mendorong sekolah agar secara intens meminta pendapat pokja PHBS di sekolah dan lakukan kajian terhadap masalah yang ditemukan; (3) Mendorong sekolah untuk memutuskan apakah perlu penyesuaian terhadap kebijakan; (4) Membantu sekolah mendapat dukungan dari Pemerintah Kota Palangka Raya, serta seluruh stakeholder yang terkait.

\section{Tahap tindak lanjut}

Tercapainya target program pada suatu kasus studi belum dapat dijadikan sebagai indikator keberhasilan program dalam kerangka yang lebih luas. Begitu banyak persoalan yang dihadapi masyarakat baik sosial kemasyarakatan maupun masalah fisik lingkungan yang belum tersentuh sehingga menjadi kendala bagi penerapan PHBS di sekolah khususnya di MI Hidayatul Insan Palangka Raya. Evaluasi dilakukan dalam 2 (dua) tahap, yaitu pada tahap pelaksanaan dan pada tahap setelah kegiatan pengabdian. Pada tahap pelaksanaan kegiatan, tim secara acak memberikan pertanyaan kepada siswa, guru atau petugas UKS tentang penerapan PHBS di sekolah. Akhir kegiatan tim memberikan kesimpulan bahwa siswa, guru dan petugas UKS telah memahami indikator pelaksanaan PHBS di sekolah.

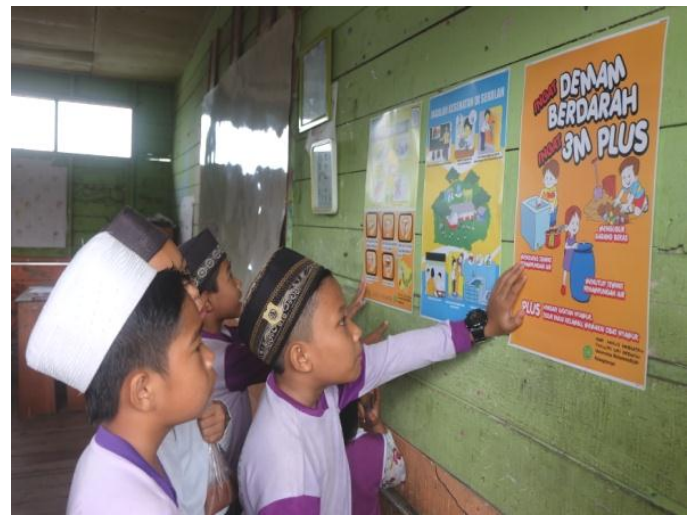

Gambar 6. Penempatan poster-poster PHBS di kelas untuk meningkatkan pemahaman siswa-siswi terhadap PHBS di sekolah

\section{Evaluasi}

Tahap evaluasi, tim pengabdian kepada masyarakat melakukan kunjungan ke MI Hidayatul Insan Kota Palangka Raya untuk melihat sejauh mana penerapan PHBS meskipun kegiatan pendampingan telah selesai. Evaluasi tahap kedua merupakan upaya tim pengabdian kepada masyarakat untuk menjaga komitmen sekolah untuk mewujudkan lingkungan sekolah yang bersih dan sehat. Kegiatan pengabdian kepada masyarakat menghasilkan beberapa luaran yaitu: 1). penerapan PHBS dalam kehidupan sehari-hari; 2). lingkungan sekolah yang bersih dan sehat; 3). meningkatnya prestasi akademik siswa; dan 5). meningkatnya animo masyarakat untuk menyekolahkan anaknya di MI Hidayatul Insan Kota Palangka Raya. 


\section{SIMPULAN DAN SARAN}

\section{Simpulan}

Kegiatan pengabdian kepada masyarakat ini menghasilkan simpulan bahwa:

1. Kegiatan pengabdian kepada masyarakat dalam bentuk pembinaan dan pendampingan Perilaku Hidup Bersih dan Sehat (PHBS) di MI Hidayatul Insan ini telah dilaksanakan dengan baik, dimana semua pihak yang terlibat sangat antusias dan berperan aktif dalam kegiatan tersebut.

2. Kegiatan pengabdian kepada masyarakat ini dilaksanakan melalui beberapa tahap yaitu persiapan kegiatan, pelaksanaan dan evaluasi.

3. Luaran kegiatan pengabdian kepada masyarakat diperoleh informasi bahwa warga sekolah telah menerapkan PHBS dalam kehidupan sehari-hari, lingkungan sekolah yang bersih dan sehat; meningkatnya prestasi akademik siswa; dan meningkatnya animo masyarakat untuk menyekolahkan anaknya di MI Hidayatul Insan Kota Palangka Raya.

\section{Saran}

Untuk menjaga penerapan PHBS dilaksanakan secara berkesinambungan, maka saran yang dapat diberikan adalah:

1. Perlu dilakukan monitoring dan evaluasi secara terus menerus terhadap keberlanjutan program penerapan PHBS di MI Hidayatul Insan Kota Palangka Raya;

2. Indikator PHBS di sekolah perlu diintegrasikan dalam kurikulum sekolah sehingga mudah dipahami oleh siswa sekolah.

\section{UCAPAN TERIMA KASIH}

Ucapan terima kasih disampaikan kepada Universitas Muhammadiyah Palangkaraya yang telah memfasilitasi dan membantu pendanaan pembiayaan kegiatan pengabdian kepada masyarakat pada Tahun Anggaran 2015 ini. Terimakasih juga disampaikan kepada pihak $\mathrm{MI}$ Hidayatul Insan Kota Palangka Raya beserta guru, siswa dan unsur pendukungnya yang secara aktif berpartisipasi pada kegiatan pengabdian kepada masyarakat ini.

\section{DAFTAR PUSTAKA}

Badan Pusat Statistik. 2013. Survei Sosial Ekonomi (Susenas) Tahun 2013. Badan Pusat Statistik. Jakarta.

Depkes R.I. 2009. Panduan Pengelolaan Pusat Informasi dan Konseling Kesehatan Lingkungan. Direktorat Remaja: BKKBN. Jakarta.

Diana, F.M., F. Susanti, dan A. Irfan. 2013. Pelaksanaan Program Perilaku Hidup Bersih dan Sehat (PHBS) di SD Negeri 001 Tanjung Balai Karimun. Jurnal Kesehatan Masyarakat, 8 (1): 46-51.

Kemenkes R.I. 2011. Promosi Kesehatan di Daerah Bermasalah Kesehatan Panduan Bagi Petugas Kesehatan di Puskesmas. Jakarta.

Kemenkes R.I. 2013. Perilaku Merokok Masyarakat Indonesia. Pusat Data dan Informasi Kementerian Kesehatan Republik Indonesia. Jakarta.

Kemenkes R.I. 2013. Profil Kesehatan Indonesia Tahun 2013. Kementerian Kesehatan Republik Indonesia. Jakarta.

Kemenkes R.I. 2013. Riset Kesehatan Dasar (Riskesdas) Tahun 2013. Badan Penelitian dan Pengembangan Kesehatan, Kementerian Kesehatan R.I. Jakarta. 
Sulastri, K., I. N. Purna, dan I. N. G. Suyasa. 2014. Hubungan Tingkat Pengetahuan dengan Perilaku Anak Sekolah tentang Hidup Bersih dan Sehat di Sekolah Dasar Wilayah Puskesmas Selembang Timur II. Jurnal Kesehatan Lingkungan, 4 (1): 99106. 